\title{
Punished avoidance behavior in the presence of a non-punished alternative
}

JACK SANDLER AND ROBERT S, DAVIDSON

VA HOSPITAL, CORAL GABLES, FLORIDA

Following the achievement of a bar press avoidance criterion, three marmoset monkeys were exposed to gradually increasing intensities of response shock. After response rates stabilized, a non-punished avoidance bar was introduced. No evidence of a response shift occurred through 19 sessions (1900 trials), although two Ss made occasional unpunished avoidance responses, and the third $S$ suddenly shifted to the unpunished bar in the 20th session. Thus, punished avoidance behavior was maintained over a relatively long time despite the non-punished alternative. The final differences were explained in terms of reinforcing and aversive interactions.

Bar press avoidance behavior may be maintained during punished training as well as during punished extinction (Sandler et al, 1966a, c). These studies, however, did not provide an unpunished avoidance alternative. Consequently, at least during punished training, there was no unpunished option available to the $S$; either he responded and received punishment or he refrained from responding and received punishment. The current study investigated the maintenance of punished bar press avoidance behavior in the presence of a non-punished alternative.

Method

Three adult, male marmoset monkeys served as Ss. A detailed description of the apparatus is provided elsewhere (Sandler et al, 1966a).

Each $S$ was trained to bar press to escape a .30 sec shock of $.80 \mathrm{~mA}$ intensity. The shock was preceded by an audible 5 sec tone, and each daily session involved 100 tone-shock trials, with time between trials varying from 18 to $42 \mathrm{sec}$ around a mean of $30 \mathrm{sec}$. Subsequent to 30 consecutive, short latency (2 sec) escape responses, the shock intensity was raised to $1.60 \mathrm{~mA}$ and avoidance training initiated. Any response during the tone terminated the tone and enabled shock avoidance. Training continued until all Ss were functioning at a $90 \%$ or better avoidance rate and variability in total bar press rate was less than $5 \%$ through 10 consecutive sessions.

Each response was then punished by a mild shock (.40 mA in intensity and $.30 \mathrm{sec}$ in duration). After baseline rates were recaptured, two additional increases in punishment intensity were introduced. Previous research demonstrated that avoidance rates could be maintained under these conditions (Sandler et al, 1966c). The final punishment intensity was 1.2 mA (75\% punishment). The punished training data are summarized in Table 1.
Following the re-establishment of baseline rates in the third punishment condition, a second bar was introduced into the chamber, approximately $4 \mathrm{in}$. to the left of the punishment bar. Both bars had identical physical and functional characteristics, the only difference being their placement in the chamber and the absence of punishment on the new bar. Thus, any response on the new bar during the tone would provide for shock avoidance without punishment.

These conditions were maintained for at least 28 sessions. Total responses, avoidance responses, and intertrial responses on each bar were recorded. Resulis

The number of avoidance responses per session on each bar during the final phase of the study are presented in Fig. 1. There is little evidence of any permanent shift to the unpunished bar by any of the Ss through the first 19 sessions of this condition. Up to that point, Ss 24 and 28 made several successful avoidance responses on the unpunished bar and were somewhat variable in their avoidance on the punished bar. On the other hand, during the same period of time, S 112 made no avoidance responses on the unpunished bar. In addition, this S's avoidance behavior on the punished bar was quite stable, falling below $99 \%$ in only one session.

As a consequence, each of the three animals experienced at least 1700 self-administered punishments despite the availability of a non-aversive alternative.

During the remainder of the study, Ss 24 and 28 continued to work, almost exclusively, on the initial avoidance bar, thereby increasing the number of self-administered punishments. In dramatic contrast, $S 112$ made 38 avoidance responses on the unpunished bar during the 20th session. Thereafter, this animal's rapid shift to the unpunished bar is reflected by a sharp, negatively accerelerated curve. By the 25th

Table 1. Mean total bar press and avoidance rates during the last five sessions of the three punished training conditions-one bar available

\begin{tabular}{|c|c|c|c|c|c|c|}
\hline \multirow[b]{2}{*}{$\begin{array}{l}\text { Punishment } \\
\text { Conditions }\end{array}$} & \multicolumn{2}{|c|}{$\# 24$} & \multicolumn{2}{|c|}{$\# 28$} & \multicolumn{2}{|c|}{$\# 112$} \\
\hline & & $\begin{array}{c}\text { Bor } \\
\text { Presses }\end{array}$ & Avd.\%. & $\begin{array}{c}\text { Bar } \\
\text { Presses }\end{array}$ & Avd. $\%$ & $\begin{array}{c}\text { Bar } \\
\text { Presses }\end{array}$ \\
\hline $\begin{array}{l}25 \% \\
(.40 \mathrm{ma})\end{array}$ & 98.2 & 106.4 & 98.0 & 107.2 & 100.0 & 101.8 \\
\hline $50 \%$ & 100 & 101 & 058 & 1126 & 1000 & 1016 \\
\hline $\begin{array}{l}75 \% \\
(1.20 \mathrm{ma})\end{array}$ & 98.6 & 107.6 & 97.6 & 102.2 & 99.6 & 105.0 \\
\hline
\end{tabular}




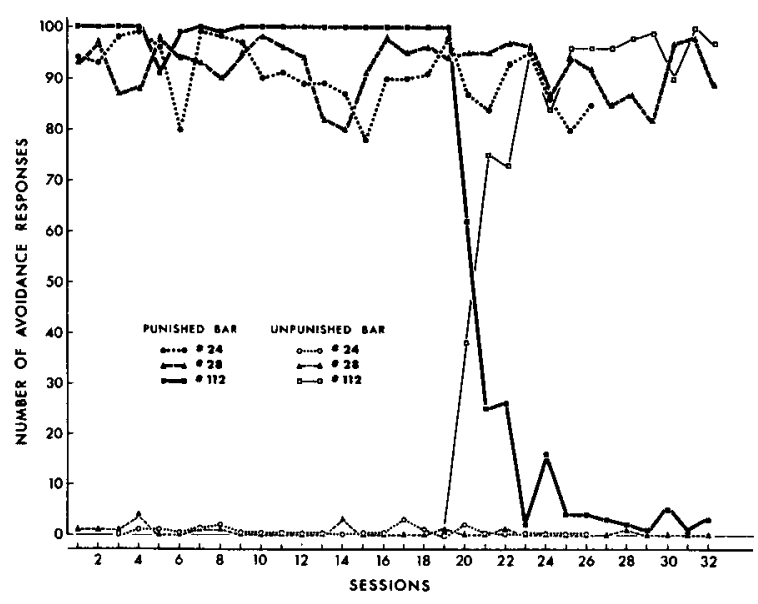

Fig. 1. Total number of avoidance responses on the punished and unpunished bar for each $\mathbf{S}$.

session, S 112 was working almost exclusively on the unpunished bar, although it occasionally returned to the punished bar through five more sessions. Discussion

The results reveal that punished avoidance behavior may be maintained despite the presence of a nonpunished alternative, at least for a relatively long period of time. The findings expand the results of earlier efforts which reveal the effect of punishment intensity (Sandler et al, 1966a), avoidance schedule (Sandler et al, 1966b), and randomly alternating unpunished avoidance trials with punished extinction trials (Sandler et al, 1966c) on the maintenance of punished avoidance behavior.

The inclusion of a non-punished alternative provides a more realistic analog of human circumstances, and the persistence of punished behavior where an unpunished avoidance alternative is available represents a neurotic reaction to the situation (Mowrer, 1948).

It is difficult to account for the dramatic differences between $\mathrm{S} 112$ and the other two Ss which occurred in the latter stage of the study. It is interesting to note that the one $\mathrm{S}$ who made the shift to the alternate bar made no previous responses to that bar, and maintained a high, stable punished avoidance rate. The other two Ss, on the other hand, made several successful avoidance responses on the unpunished bar and were more variable in their punished avoidance rates, yet they did not shift. In terms of general reinforcement theory, one might ordinarily predict that Ss who experienced unpunished avoidance would shift more rapidly than the $S$ who never avoided on the unpunished bar, and it is difficult to resolve the findings with theory. However, some clarification may be obtained by considering the possible reward and punishment interactions which may occur under these circumstances. Thus, if only a few responses on the unpunished bar provided avoidance, and the majority were intertrial responses, then the latter may be inadvertently punished by trial run-outs. It is reasonable to assume, then, the alternate bar acquired both reinforcing as well as aversive properties, but the net effect was aversive. The result would be a return to the punishment bar, where $S$ could, at least, control the delivery of punishment. On the other hand, if $S$ had no history of responding on the alternate bar, then its reinforcing and aversive properties were neutralized. Consequently, the net effect of the first response on that bar, should it be of the avoidance variety, would be highly reinforcing, thus increasing the probability of further responses to the unpunished bar.

There is some evidence to support this proposal. Over the first 19 sessions of the final stage, both Ss 24 and 28 made a total of 279 and 75 alternate bar responses, respectively, less than $20 \%$ of which were successful unpunished avoidance responses. During the same time $\mathrm{S} 112$ made only 14 such responses, all of which occurred during the first five sessions. No alternate bar responses were made during the next 14 sessions, and the first response to the unpunished bar in the next session was of the avoidance variety.

While this is hardly conclusive evidence, the data suggest that complex reinforcing and aversive interactions govern the behavior of organisms functioning under these conditions, and any attempt to predict such choice behavior, for example, must attempt to analyze these interactions.

\section{References}

Mowrer, O. H. Learning theory and the neurotic paradox. Amer. J. Ortho., 1948, 18, 571-609.

Sandler, J., Davidson, R. S., Greene, W. E., \& Holzschuh, R. D. Effects of punishment intensity on instrumental avoidance behavior. J. comp. physiol. Psychol., 1966a, 61, 212-216.

Sandler, J., Davidson, R. S., \& Holzschuh, R. D. Effects of increasing punishment frequency on Sidman avoidance behavior. Psychon. Sci., 1966b, 5, 103-104.

Sandler, J., Davidson, R. S., \& Malagodi, E. F. Durable maintenance of behavior during concurrent avoidance and punishedextinction conditions. Psychon. Sci., 1966c, 6, 105-106. 